\title{
The 3D Numerical Simulation of the Shaped Charge Jet Penetration through the Steel Target
}

\author{
Huang Junqing \\ Department of Equipment Command and Administration \\ AAFE \\ Beijing, China \\ e-mail: tigerhjq@126.com
}

Wang Wenyue

Department of Equipment Command and Administration AAFE

Beijing, China

e-mail: xyz@126.com

\author{
Zhang Wei \\ Department of Equipment Command and Administration \\ AAFE \\ Beijing, China \\ e-mail: ccc@126.com \\ Huang Kelei \\ Department of Equipment Command and Administration \\ AAFE \\ Beijing, China \\ e-mail: abc@126.com
}

\begin{abstract}
In this paper, adopted explicit dynamic analyzing program AUTODYN basing on finite element to simulate the process of the shaped charge jet formation and the penetration through the steel target, base on the characteristic of the shaped charge structure and the mechanisms of jet penetrating the target. Adopted ALE ( Arbitrary Lagrange Euler) arithmetic to acquire numerical simulation results. By analyzing, the simulation result that the shaped charge jet formation is basically accordant by contrasting the physical phenomenon and rule. At one time, the result that the target be damaged is basically same by contrasting the result of the trial. The simulation model and method that the shaped charge jet formation and the penetration through the target are proved to be reasonable and feasible.
\end{abstract}

\section{Keywords- the shaped charge; jet; numerical simulation}

\section{INTRODUCTION}

Currently, the armored equipment inside was damaged by the main projectile factors: flying fragments, residual energy and speed of the jet, shock waves generated by overpressure, shock and vibration and noise. For HEAT attack, jet is the most important factor of damage to components inside and the personnel. Therefore, the study of shaped charge jet formation and penetration process is of great significance.With the rapid development of computer technology, adopt the numerical simulation method to simulate the process of the shaped charge jet formation and the penetration through the target has been possible, and the numerical simulation method which is widely used in---base on finite element to simulate the process of the shaped charge jet formation and the penetration through the target, not only be propitious to read the process of jet formation and the mechanism of the penetration through the target but also will be a enormous assist to optimize the capability of projectile body. Compared with direct ways, this method is cheap and fast, the advantage was outstanding when considering more factors. AUTODYN is a explicit dynamic analyzing program, can solve many large deformation dynamic responsiveness like high-speed hits, blast, dies, metal moldings, metal incisions of kinds of planar and threedimensional non-flexible structure, was widely used in aviation, spaceflight, auto and war industries. Now adopt the explicit dynamic analyzing program AUTODYN base on finite element to simulate the process of the linear shaped charge jet formation and the penetration through the target.

\section{NUMERICAL SimUlation MODEL}

During the process of simulation analysis by finite element, the final target is going to revert one mathematic model of practical project. The analysis model includes all of the nodes, cells, materials, boundaries and other character could comport the physical identity is the crux of the simulated result.

\section{A. Material Model}

Target, liner and the shell material model with elasticplastic properties uses Johnson-Cook model. Among them,

$$
\varepsilon=\left(D_{1}+D_{2} e^{D_{3} \sigma^{*}}\right)\left(1+D_{4} \ln \varepsilon^{*}\right)\left(1+D_{5} T^{*}\right)
$$

Where, $\varepsilon$ is the fracture strain, D1 D5 is the materialrelated constant; $\varepsilon *$ is the effective plastic strain rate; $T^{*}$ is the relative temperature; $\sigma *$ is the compressive stress and effective stress ratio:

$$
\sigma^{*}=p / \sigma_{e f f}
$$

Let damage degree $\mathrm{D}$, and there

$$
D=\sum \frac{\Delta \bar{\varepsilon}^{p}}{\varepsilon}
$$

Where, $\bar{\varepsilon}^{p}$ is the effective plastic strain, the material begin to break up when the damage degree of $\mathrm{D}$ up to 1 .

Johnson-Cook material model contains five material constants: A, B, C, n, m. Where, A is for small strain yield stress of materials under conditions of constant, B is for the the material fracture strain when expression is: 
material strain hardening coefficient, $\mathrm{n}$ is for the material strain hardening exponent, $\mathrm{C}$ is for the correlation coefficient of the material strain rate, $\mathrm{m}$ is for the compared temperature coefficient materials. Liner material is copper, target and the shell material is a steel, the main parameters of their Johnson-Cook model is in Table .

TABLE I. THE TARGET AND LINER MATERIAL JOHNSON-COOK MODEL PARAMETER

\begin{tabular}{|c|c|c|c|c|c|c|c|}
\hline material & $\rho$ & $\mathrm{A}$ & $\mathrm{B}$ & $\mathrm{c}$ & $\mathrm{n}$ & $\mathrm{m}$ & $\mathrm{T}$ \\
\hline CU-OFHC $_{\mathrm{m}}$ & 8.96 & 1425 & 168 & 0.032 & 0.12 & 1.0 & 1356 \\
\hline Steel $^{1 \#}$ & 7.8 & 1600 & 220 & 0.02 & 0.08 & 1.0 & 1520 \\
\hline Steel $^{2 \#}$ & 7.83 & 1556 & 210 & 0.02 & 0.06 & 1.0 & 1450 \\
\hline
\end{tabular}

The outcome of the shaped charge blast could be described as JWL state equation and formula (4) below, its material parameter refer to table II, adopted by $\mathrm{cm}$-g-us unitage.

$$
P=A\left(1-\frac{w}{R_{1} V}\right) e^{-R_{1} V}+B\left(1-\frac{w}{R_{2} V}\right) e^{-R_{2} V}+\frac{w E}{V}
$$

Table II. MATERIAL PARAMETER OF TNT

\begin{tabular}{|c|c|c|c|c|c|c|c|}
\hline$P_{0}$ & $\mathrm{D}$ & $\mathrm{A}$ & $\mathrm{B}$ & $\mathrm{R}_{1}$ & $\mathrm{R}_{2}$ & $w$ & $\mathrm{E}_{0}$ \\
\hline 1.63 & 0.693 & 3.74 & 0.0323 & 4.15 & 0.95 & 0.3 & 2.7 \\
\hline
\end{tabular}

\section{B. Finite Element Model}

The calculation model as Figure 1. The numerical value model was adopted by mm-mg-ms unitage. Material models of the detonator, the shaped charge liner and the shell adopt Euler modeling, element's arithmetic make use of multi-material ALE (Arbitrary Lagrange Euler), the steel target adopts Lagrange arithmetic modeling for the sake of describing exactly structural boundary of the target being penetrated, the mutual effect in the materials of the steel target and the shaped charge liner adopt coupling arithmetic, the way to ignition is along the top coping. The calculate gridding of the detonator, the shell, the shaped charge liner and the steel target are all hexahedron cell. The calculate model was carved up to 790315 griddings. For improving computing efficiency, built 2D armour model. Adopted 2D numerical simulation way to simulate the process of jet formation. In order to improve solution efficiency, the establishment of two-dimensional warhead model is there. Jet formation process of two-dimensional uses the numerical simulation method, when the jet formated and stretched, with two - three dimensional mapping technology,
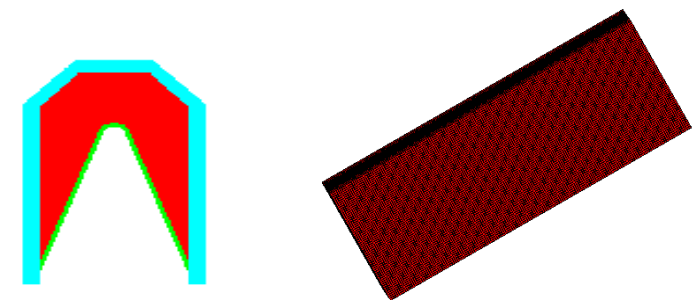

(a) Warhead model

(b)target model

Figure 1 Sketch of shaped charge jet model

the two-dimensional numerical simulation of the jet is mapped to the environment, achieving three-dimensional jet simulation Penetrate Target.

\section{NUMERICAL SimUlation RESUlts AND ANALySES}

\section{A. Process of Jet Formation and Elongation}

Figure. 2 shows the jet in different time status in process of it formation and elongation. When $\mathrm{t}=14 \mu \mathrm{s}$, the dynamite explosion is almost complete. By the action of the explosion result, the metal covering moves to the axes trace of the dynamite and gets to circled. Nose shape of the jet then just appears. When $t=24 \mu \mathrm{s}$, metals at the inner side of the shaped charge liner is pushed out shaping into carrot and increases the mass of the jet. Due to the dynamite in the centre is more powerful than the surrounded, the two sides of the metal covering which is closed to the top is more influenced and gets more shape change with being increasing. In the process of the jet stretching, at the same time the mass of carrot is also growing. When $\mathrm{t}=34 \mu \mathrm{s}$, the slower metal jet forms a carrot that takes up almost $2 / 3$ of the whole shaped charge liner's mass. Because of the very speed difference between the head and the tail, it is possessed of great velocity grads. When $\mathrm{t}=56 \mu \mathrm{s}$ comes, the top of the jet emerges an abruptment.
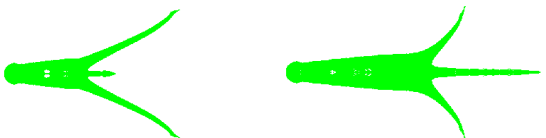

$\mathrm{t}=14 \mu \mathrm{s}$

$\mathrm{t}=24 \mu \mathrm{s}$
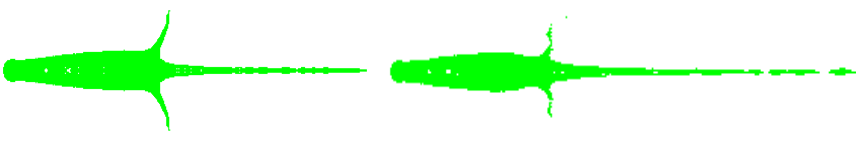

$\mathrm{t}=34 \mu \mathrm{s}$

$\mathrm{t}=56 \mu \mathrm{s}$

Figure 2 The forming process of the jet

Figure. 3 is the kinetic energy of jet formation changes over time. From Fig.4: During the $0 \sim 0.007 \mathrm{~ms}$ period, the jet has not yet formed, so the jet kinetic energy is 0 $\mathrm{kJ}$; during the $0.007 \sim 0.026 \mathrm{~ms}$ period, the explosive burst of static, liner crushed, micro-element liner Overlay of the normal direction along the plastic flow, and convergence in 
the axis along the movement, so this time the jet kinetic energy increases rapidly, almost linear rise, reaching $300 \mathrm{~kJ}$; during the $0.026 \sim 0.038 \mathrm{~ms}$ period, reaching Detonation maximum kinetic energy to stabilize the jet, this time corresponding to the favorable high bombing, that $/ \mathrm{s}$ the time Jet Penetrate Target will achieve the best results. after this period the energywill be reduced.

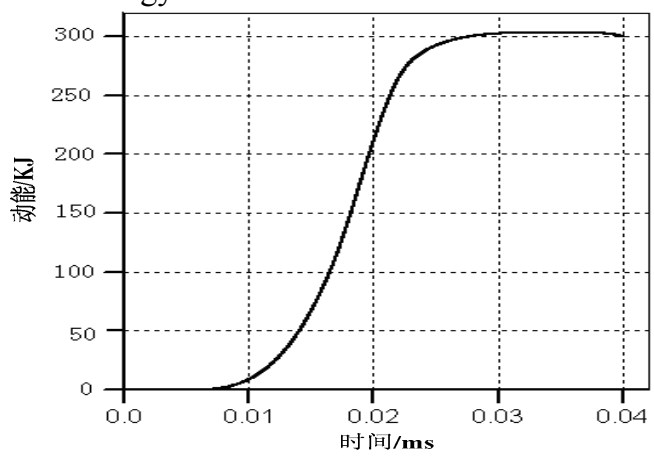

Figure 3 The kinetic energy of jet formation changes over time

\section{B. Process of Jet Penetrating}

Figure. 4 shows the result of simulating process while jet penetrating the target. It contains 3 phases. At the first phase that the jet start to penetrate the target, the jet impact the target. Due to the high speed of the its nose, a plastic deformation area is momentarily presented surrounding it as Figure.4(a).Then the next phase that the jet penetrate the target when the target being in state of high pressure, high temperature and high strain rate. The reduced shearing strength is specially to the advantage of penetrating as Figure.4(b).The last is the penetrating expiration, which is a quite complex phase. The velocity reduction leads to the target's strength improved and the chambering decrease. Follow-up jet catches up with the previous that has already released energy and continue penetrating as Figure.4(c).

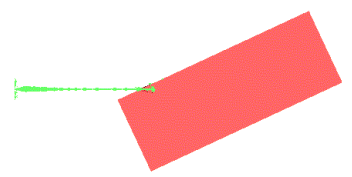

(a)
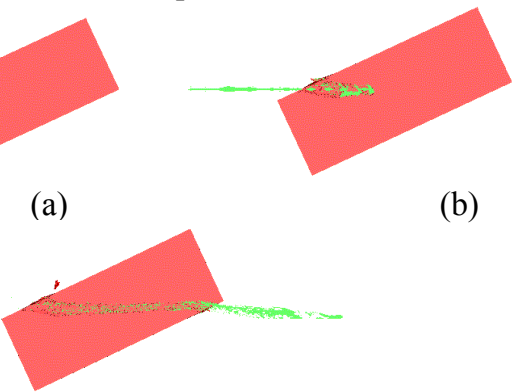

(c)

Figure 4 The process of the jet penetration the steel target

Test data by comparing with the simulation results, which verifies the reliability of numerical simulation model. Experimental conditions, the live test results and simulation results are in Table III. HEAT Jet Penetration into Target and the aftereffect of the state after the target (simulation results) are in Figure.5. The stretching length of the period between target and the aftereffect jet in penetrating is $775 \mathrm{~mm}$.

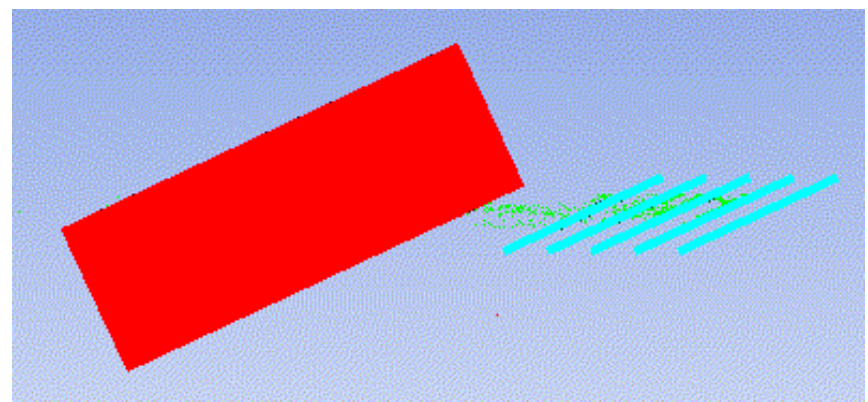

Figure 5 The status of the jet penetration the steel target and the aftereffect target ( simulation result)

TABLE III. THE TEST CONDITION AND THE COMPARISON RESULT ABOUT THE TEST DATA AND THE SIMULATION DATA

\begin{tabular}{|c|c|c|c|c|c|c|c|}
\hline \multicolumn{4}{|c|}{ test condition } & \multicolumn{2}{|c|}{$\begin{array}{c}\text { The target } \\
\text { whether or not be } \\
\text { penetrated }\end{array}$} & $\begin{array}{c}\text { layer Number of } \\
\text { the aftereffect } \\
\text { target penetrated }\end{array}$ \\
\hline $\begin{array}{c}\text { pill } \\
\text { type }\end{array}$ & $\begin{array}{c}\text { mass of the } \\
\text { TNT }\end{array}$ & $\begin{array}{c}\text { Thickne } \\
\text { ss of the } \\
\text { target }\end{array}$ & $\begin{array}{c}\text { incid } \\
\text { ence } \\
\text { angle }\end{array}$ & $\begin{array}{c}\text { test } \\
\text { result }\end{array}$ & $\begin{array}{c}\text { simula } \\
\text { tion } \\
\text { result }\end{array}$ & $\begin{array}{c}\text { test } \\
\text { resul }\end{array}$ & $\begin{array}{c}\text { simulat } \\
\text { ion } \\
\text { result }\end{array}$ \\
\hline $\begin{array}{c}\text { HEA } \\
\text { T }\end{array}$ & $1.716 \mathrm{~kg}$ & $180 \mathrm{~mm}$ & $68^{\circ}$ & $\begin{array}{c}\text { penetr } \\
\text { ation }\end{array}$ & $\begin{array}{c}\text { penetr } \\
\text { ation }\end{array}$ & 4 & 3 \\
\hline
\end{tabular}

\section{CONCLUSIONS}

Adopting explicit dynamic analyzing program AUTODYN base on finite element to simulate the process of the linear shaped charge jet formation and the penetration through the target. Some problem, such as computation failure due to element grid being destroyed seriously can be solved by making use of multi-material ALE (Arbitrary Lagrange Euler). The computing results are consistent with the physical discipline and test outcome of jet charge. At the same time, the simulation result of the jet penetrating the target is basically consistent by comparing with physical test result. Above all proves that the modeling and numerical simulation method are correct. They can supply support for research the mechanisms of jet penetrating the target and aftereffect.

\section{REFERENCES}

[1] Taylor L M, Chen E P, Kuszmaul J S, Microcrack-induced damage accumulation in brittle rock under dynamic loading[J]. Journal of Computer Methods in Applied Mechanics and Engineering, 1986,55(3):301-320.

[2] Holmquist T J, Johnson Dr G R, Cook Dr W H. A computational constitutive for concrete subjected to large strains, high strain rates and high pressure[C] // Proceeding of the Fourteenth International Symposium on Ballistics. USA: American Defense Prepareness Association, Quebec, Canada,1993,2:591-600.

[3] Budiansky B, o' Connell R J. Elastic Moduli of a Cracked Solid[J].Int J Solids Struct, 1976,12:81-97

[4] Grady D E, Kipp M E. Continuum Modeling of Explosive Fracture in Oil Shale[J]. International Journal of Rock Mechanics and Mining Science, 1980,17:147-157.

[5] Grady D E. The Mechanics of Fracture under High-Rate Stress Loading [A] // Preprints of the Willian Prager Symposium on 
Mechanics of Geomaterials:Rocks,Concrete and Soils[C].Evanston, Illinois:Northweatern University,1980:149-188

[6] Hans E.V. Karless, Computer Simulation of Shaped Charge Jet Fragmentation[A].19th Inter-national Symposium of Ballistics[C]. Interlaken. Switzerland, 2001.
[7] A.Blache, K.Weimann. Shaped charge with jet-ting projectile for extended targets[A].17th Inter-national Symposium on Ballistics. Midrand. South Africa[C].1998.

[8] Hirt C W. Amsden A A. Cook J L. An arbitrary Lagrangian Eulerian computing method for all flow speeds[J]. J Computational Physics, 1974,14:227 253 